\title{
第一原理擬ポテンシャル法による セラミックス界面の研究
}

香 山 正 憲*

\section{1. は じめに}

Car-Parrinello の方法(1)の開発以来，第一原理擬ポテンシ ャル法の適用範团は, 従来の限界を超えて大きく広がってい る. 各種物質の構造や性質, 格子欠陥や表面の静的·動的な 性質, アモルファスや粒界, 異種物質界面といった複雑構 造, 各種反応等々, 物性研究のみならず実用的な材料研究の 領域にも進展しつつある ${ }^{(2)}$. 第一原理擬ポテンシャル法は, 第一原理計算の中ではプログラム構築が比較的容易であり, 沉用性も高く，固体を扱ら一つの標準的な手法になりつつあ る. 本稿では, まず，第一原理擬ポテンシャル法による大規 模構造計算ついて, 方法の概要を説明する。これから計算を 開始する人に役立つように記述したい，次に，筆者らによる セラミックス界面への適用例(3)(4)を紹介する.

\section{2. 第一原理擬ポテンシャル法による大規模構造計算}

\section{（1）第一原理擬ポテンシャル法の原理}

擬ポテンシャル法は価電子のみを扱う半経験的バンド計算 法として，半導体等に長く用いられてきた. Hamann らに よるノルム保存擬ポテンシャル(5)の構築により, 密度汎関数 理論に基づく第一原理計算法として確立された. 概要を紹介 するレビューとして文献(6)(7)がある. 基本原理は文献 (8) に分かりやすく説明されている，まず，孤立原子やイオンの 全電子軌道計算から始める。価電子軌道毎に, 半径 $r_{\mathrm{c}}$ 内で ノルム保存条件を満たし， $r_{\mathrm{c}}$ 外で真の原子波動関数に一致
し，正しい固有エネルギー $\varepsilon$ を持ち，かつノードを持たない 擬(偽の) 原子波動関数を組み立てる. 同時に, そらした擬波 動関数を生むよらな原子ポテンシャル(擬ポテンシャル)を構 築する. このとき, この擬ポテンシャルが $\varepsilon$ の付近で内殼領 域の散乱の性質を正しく再現することが証明される.したが って, 価電子に働く内殸からのポテンシャルとして, この擬 ポテンシャルを固体に埋め込んで使用することができる.

殼付近でノードを持たない解を生むので, 波動関数が平面 波基底だけで展開できる。これは極めて大きな利点である。 ハミルトニアン $H$, 全ェネルギー $E_{\mathrm{tot}}$, 原子に働く力, 応力 テンソル等々が各種行列要素とベクトル(平面波基底の展開 係数)でシンプルに表され, さらに高速フーリェ変換 $(\mathrm{FFT})$ を駆使して実空間と逆空間の演算を使い分けることにより， 計算の大きな効率化が可能になる(6)(7)(9). また，擬ポテンシ ヤルは角運動量成分への射影演算子を含む非局所項と, 含ま ない局所項からなるが，非局所ポテンシャルを分離型(10)で 用いることにより，さらなる効率化が可能である.

\section{（2）高速計算技法}

しかし, 大規模構造の取り扱いは基底数が膨大になり容易 ではない，適当な打ち切りエネルギー $E_{\mathrm{cut}}=\hbar^{2}|\boldsymbol{k}+\boldsymbol{G}|^{2} / 2 m$ 以下の平面波基底 $|\boldsymbol{k}+\boldsymbol{G}\rangle$ を用いるが， $\boldsymbol{G}$ 点密度から基底数 はセルの大きさに比例することになる．また，第一周期元素 や遷移金属元素など価電子が比較的局在する元素を扱う場 合，短波長(大きな $\boldsymbol{G}$ )の平面波が必要で， $E_{\text {cut }}$ を大きくせね ばならない。これらの問題を解決し, 大規模構造の格子緩和 計算や分子動力学計算を可能にする計算技術が，いわゆる

* 大阪工業技術研究所材料物理部主任研究官(示563-8577 池田市緑ケ丘1-8-31)

Theoretical Study of Ceramic Interfaces Using Ab Initio Pseudopotential Method; Masanori Kohyama(Osaka National Research Institute, AIST, Ikeda)

Keywords: ab initio pseudopotential method, first-principles molecular dynamics method, ceramics, grain boundary, SiC, SiC-metal interface 1998年 3 月 13 日受理 
「第一原理分子動力学法」である. 効率的に電子の基底状態 を求める高速計算技法と, 平面波基底数を減らすソフト擬ポ テンシャルの構築技術からなる. 解説として文献 (11)-(14) がある。

高速計算技法について, Car-Parrinello 法以降, 多くの改 良手法やアルゴリズムが提案されている. 基本原理は, 電子 系の Lagrangian から説明する場合が多いが，以下のように 全エネルギー $E_{\mathrm{tot}}$ の変分から考光ると直観的に分かりやす い. 密度汎関数理論加 $5, E_{\text {tot }}$ は原子位置 $\left\{R_{\mathrm{I}}\right\}$ と電子密度分 布関数 $\rho(\boldsymbol{r})$ の沉関数であり, 固定した $\left\{R_{\mathrm{I}}\right\} に つ い て E_{\mathrm{tot}}$ を 最小にする $\rho(\boldsymbol{r})$ が基底状態の正しい $\rho(\boldsymbol{r})$ である. $\rho(\boldsymbol{r})$ が占 有された一電子波動関数 $\phi_{i}(\boldsymbol{r})$ のセットで

$$
\rho(\boldsymbol{r})=\sum_{i}^{\mathrm{occ}}\left|\phi_{i}\right|^{2}
$$

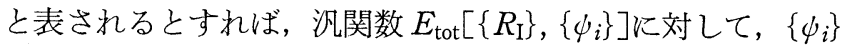
についての規格直交条件付の最小化を行光ば，正しい $\left\{\phi_{i}\right\}$ が 求まることになる. Lagrange 未定係数法から，

$$
\Omega=E_{\mathrm{tot}}-\sum_{i, j} \lambda_{i j}\left(\left\langle\psi_{i} \mid \psi_{j}\right\rangle-\delta_{i j}\right)
$$

を扱う。規格直交条件を別過程で付加するとして，変分は，

$$
\delta \Omega / \delta \phi_{i}^{*}=H \phi_{i}-\lambda \phi_{i}
$$

になる。ここで, $\delta E_{\text {tot }} / \delta \phi_{i}^{*}=H \psi_{i}$ であり, $\lambda=\left\langle\phi_{i}|H| \phi_{i}\right\rangle$ で ある。

式( 3 )をそのままゼロに打けば Kohn-Sham 方程式にな る. 従来のバンド計算ではこれを固有値問題にして解いてい た. 高速計算技法では, 式 ( 3 )のー $\delta \Omega / \delta \phi_{i}^{*}$ が, $E_{\text {tot }}$ を最小 にする方向で $\phi_{i}$ に作用する “力”と見なせることを利用す る. 適当な input $の\left\{\phi_{i}\right\}$ 加出発して, “力” に従って $\left\{\phi_{i}\right\}$ を徐々に変化させ, 最終的に式 $(3)$ をゼ口にする $\left\{\phi_{i}\right\}$ のセ ットを求めるわけである. Car-Parrinello 法では, 式( 3 )の “力”を用いて $\left\{\phi_{i}\right\}$ についての運動方程式を組み立て, これ を数值的に解く。一方, 式(3)を勾配として使えば, 共役 勾配法による $E_{\mathrm{tot}}$ の最小化を行らことも可能である. 共役 勾配法は非線形最適化問題の効率的な数值解法である. バン ド毎 ${ }^{(12)}$ や全バンド一斉に ${ }^{(15)}$ 適用するアルゴリズムが提案さ れている.

以上のアルゴリズムは, $\phi_{i}$ の最適化過程での $\rho$ の変化 $(\rho$ に依存するポテンシャル項の変化)を $H$ に逐次に取り入れる 「直接法」であり, self-consistency が常に満たされている. 一方, 従来のバンド計算と同様に, $H$ の対角化と $H$ 内のポ テンシャルの更新を分離して行い，Hの対角化過程に高速 計算技法を適用する「間接法」もありえる。この場合，共役 勾配法は期待値の最小化の観点で適用される ${ }^{(16)}$. 適当な混 合法で $\rho$ を更新すれば，金属系が効率的に扱劣る(17).「間接 法」では, block Davidson 法など, 古くから大規模行列用 に研究されてきたアルゴリズムも各種改良されて用いられて いる(18)(19).

以上のすべての高速計算技法に共通する計算技術として，
FFT と分離型擬ポテンシャルを利用した $H \psi_{i}$ 計算の高速化 がある.FFT の利用は例党ば文献 (20) 飞説明されている。

\section{(3) ソフト擬ポテンシャル}

擬ポテンシャルの構築には本質的に任意性がある．平面波 基底を減らすようになるべく浅くスムーズで，且つ精度を保 ったものが望ましい，原子擬波動関数のフーリェ成分の収束 性を考慮するもの $\left(\mathrm{RRKJ}\right.$ 型 $\left.{ }^{(21)}\right)$ ，さらに $r_{\mathrm{c}}$ での真の波動関 数との接続条件等を工夫するもの ( $\mathrm{TM}$ 型 $\left.{ }^{(22)}\right)$ 等が提案され ている.これらはノルム保存型で，上述の $H, E_{\mathrm{tot}}$ 等の表現 がそのまま使える。

一方，ウルトラソフト擬ポテンシャル(23) は，ノルム保存 条件をはずしてソフト化を達成する．基底数の飛躍的な縮小 が可能になる。ただし，この場合，角運動量成分毎の参照エ ネルギー準位が二つ以上あること，殸付近の電荷を補正する ことなど， $H, E_{\text {tot }}$ 等の計算方法にかなりの変更が必要であ る.また，基底数は減らせるがコア付近の電荷の FFTでの 取り扱いにコストがかかり，工夫が必要になる(24)。ところ で, 文献 (23)には, 分離型擬ポテンシャルについて, 従来 のノルム保存型は非保存型の特例として包含されるとする興 味深い議論が展開されている.また，ノルム保存や非保存の 擬ポテンシャル法と，LAPW 法など全電子の方法とを統一 的に説明する新しい方法も提案されている(25).

\section{3. $\mathrm{SiC}$ 粒界の第一原理計算}

図 1 は $\operatorname{SiC}\{122\} \Sigma=9$ 粒界の非極性界面の安定構造である.

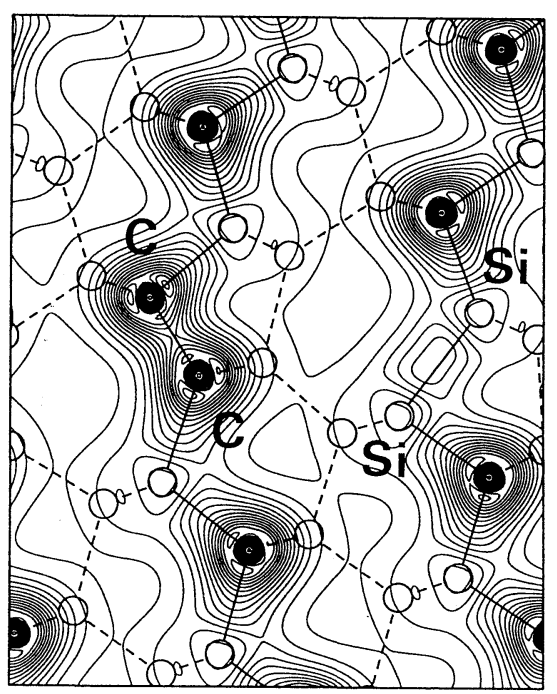

図 $1 \operatorname{SiC}\{122\} \Sigma=9$ 粒界 (非極性界面)の安定原子配列 と価電子密度分布. 電子密度は0.015から0.295 まで $0.020\left(\right.$ a.u. $\left.^{-3}\right)$ 刻み $(1$ a.u. $=0.0529 \mathrm{~nm})$. 〈011〉投影図で，二セットの五員環と七員環が一 周期を構成する。 
64 原子セルに TM 型擬ポテンシャルと共役勾配法(12)を適用 した. SiC 薄膜で類似した原子配列が観察されている(26)(27). 現実的なセラミックス粒界の第一原理計算は世界初である. 界面で全ボンドが再構成しているが，C-C, Si-Si の同種原子 ボンドが特異な様相を呈している，C-C ボンドは diamond のボンド長に近く $(+3.6 \%), \mathrm{Si}-\mathrm{Si}$ ボンドも $\mathrm{Si}$ のボンド長に 近い $(-4.4 \%)$. 価電子密度分布も diamond, $\mathrm{Si}$ のボンドに 類似している。他の Si-C ボンドのボンド長・角歪みは, 各 々 $-2.9 \% \sim+2.9 \%,-22.4^{\circ} \sim+27.9^{\circ}$ である. 界面エネルギ 一(完全結晶比のエネルギー上昇)は $1.27 \mathrm{~J} / \mathrm{m}^{2}$ で, 表面より かなり安定である、C-C ボンドは，価電子バンドの底と上端 に強い局在準位を生んでいる。この起源は, diamond の価 電子バンド幅が $\mathrm{SiC}$ のものよりかなり広いため, $\mathrm{SiC}$ の価電 子バンドの上下に diamond 的な準位がはみ出てたものと理 解できる。

ところで, 図 1 の界面の一方の結晶を反転すると二種の 極性界面が形成できる。この場合, 一方は C-C ボンドのみ, 一方は Si-Si ボンドのみを持つ. 同様の計算を行ったとこ ろ, 界面ボンドは同様に再構成し, 同種原子ボンドが類似し た様相を持つことが判明した。

図 2，3 は，図 1 の界面の「第一原理引張試験」の結果で ある，界面に垂直方向にセルを少しずつ伸ばしながら緩和計 算を繰り返したもので, 絶対零度での現実の引張試験に対応 寸る. 引張歪みが $12 \%$, 応力が $40 \mathrm{GPa}$ を越光ると C-C ボ ソドの back ボンドから破断が始まる.C-C ボンドが短く硬 いため back ボンドが大きく伸ばされ，ボンド伸びが $20 \% を$ 越光ると一気に破断し，C-C ボンドは逆に縮まる。続いて界 面の Si-C ボンドが破断した.

破断する応力は実際の焼結体の実験值より桁違いに大き い，実験的には一番弱い欠陥やクラックから破断が始まるた めである.今回の界面はボンドの再構成のためかなり強いと 結論できる。「第一原理引張試験」のような計算では, 実験 では求めにくい界面や欠陷各々の本性的な強度や破壊の様相 を高精度に探ることができる，様々な粒界や偏析元素を有す る系(28)への適用が進行中であり, 今後, 材料科学への大き な寄与が期待できる.

\section{4. $\mathrm{SiC} / \mathrm{Al}$ 界面の第一原理計算}

セラミックス/金属界面は広範な分野で極めて重要であり, 界面結合のメカニズムの解明が求められている. イオン結 晶/金属界面の第一原理計算 ${ }^{(29)}$ に比べ共有結合セラミックス / 金属界面の計算はあまり行われていない(30).そこで $\mathrm{SiC}(001) / \mathrm{A} 1$ 界面の第一原理計算を行った。C-Al, Si-Alの 相互作用を明確にするため, C 原子面と $\mathrm{Si}$ 原子面各々と $\mathrm{Al}$ との界面を扱った． $\mathrm{Al}$ 側を面内に数\%歪ませた整合界面で ある. $\mathrm{SiC}(001) 9$ 原子層スラブ両面に Al 5 原子層ずつ積層 したセルに TM 型擬ポテンシャルと共役勾配法(16)(17)を適用

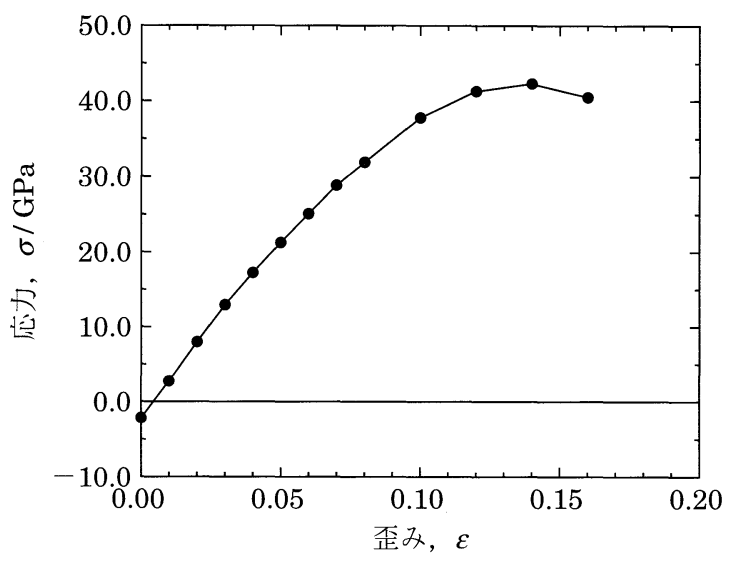

図 $2 \operatorname{SiC}\{122\} \Sigma=9$ 粒界(非極性界面)の「第一原理引 張試験」に技忷る応力-歪久曲線.

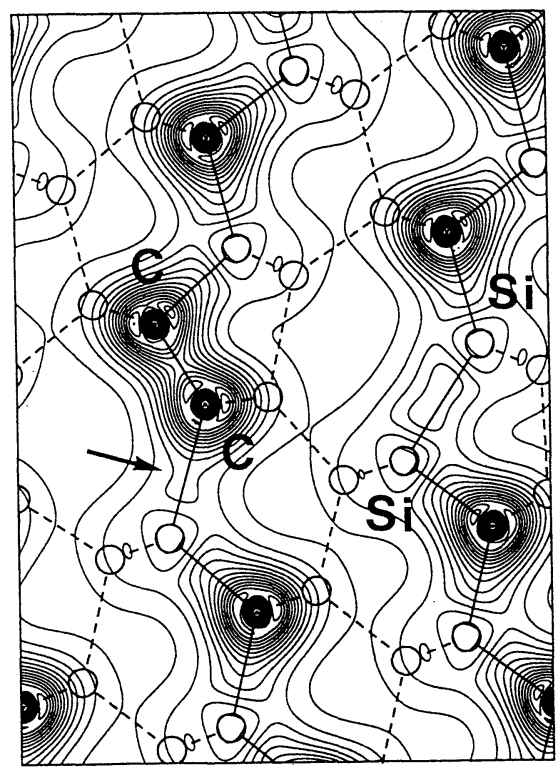

図 $3 \operatorname{SiC}\{122\} \Sigma=9$ 粒界(非極性界面)の「第一原理引 張試験」での引張歪み $12 \%$ の構造. C-C ボンド の back ボンド(矢印)が注とんど切れかかってい る.

した。

図 4 に結果を示す. C-terminated 界面では, 界面 C 原子 が三配位の構造が最安定である. C-Al 間の電子分布は $\mathrm{Si}-\mathrm{C}$ 間のものに類似して扣り，C-A1 間にも共有結合性とイオン 結合性(極性)をあわせ持つ局所的に強い結合が生じている. Si-terminated 界面では, 界面 Si 原子は四配位で, 界面結合 はむしろ金属的である。界面エネルギー（界面形成のエネル ギー利得) は前者が $6.42 \mathrm{~J} / \mathrm{m}^{2}$, 後者が $3.74 \mathrm{~J} / \mathrm{m}^{2}$ であった. $\mathrm{SiC}$ の $\mathrm{C}$ 原子面の方が $\mathrm{Al}$ と強く結合することは, 超高真空 中での表面活性化接合実験で見いだされている(31). また， これらの界面エネルギー値は， $\mathrm{Al}(001)$ 原子層間 $\left(2.04 \mathrm{~J} / \mathrm{m}^{2}\right)$ や $\mathrm{MgO}(001) / \mathrm{Al}$ 界面 $\left(1.10 \mathrm{~J} / \mathrm{m}^{2}\right)$ の計算值 ${ }^{(29)}$ より大きい. 共有結合セラミックス/金属界面はイオン結晶/金属界面より 界面エネルギーが大きいとする予想を証明するものである. 

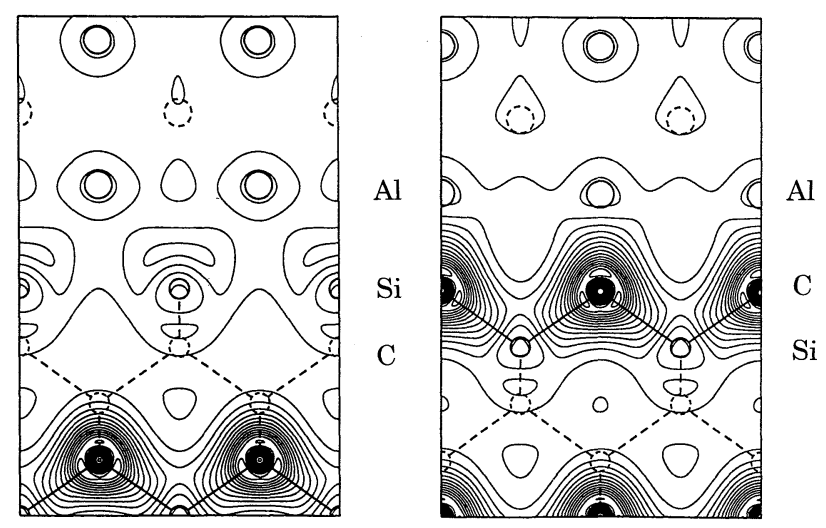

図 $4 \mathrm{SiC}(001) / \mathrm{Al}$ 界面の安定原子配列と価電子密度 分布. 左が Si-terminated 界面，右が C-terminated 界面. 各々 (110)断面, (110)断面で, 破線は 断面上にない原子を示す。電子密度は0.010から 0.270 まで 0.020 (a.u. $^{-3}$ )刻久。

今後, こうした計算による異種物質間の接合性の予測や設計 が期待できよう。

一方, 電子材料としての $\mathrm{SiC} / \mathrm{Al}$ 界面の重要な性質にショ ットキー障壁高 $(\mathrm{SBH})$ がある. 七ルのサイズや密度汎関数 理論 (局所密度近似)の問題はあるが，原子層毎の局所状態密 度の分析から SBH の理論值が求められる. C-terminated 界 面は $0.08 \mathrm{eV}$, Si-terminated 界面は $0.85 \mathrm{eV}$ であった ( $\mathrm{p}$ 型で の障壁高) $\left(1 \mathrm{eV}=1.602 \times 10^{-19} \mathrm{~J}\right)$. 後者の値は $\mathrm{SiC}(001)$ の $\mathrm{Si}$ 面での実験值 $0.9 \mathrm{eV}^{(32)}$ に近い。前者が低い理由は明白 で，図 4 に見られるようにC-A1 間の顕著な電子移動による 界面 dipole のためである. 表面の仕事関数が電子のしみ出 しによる dipole に大きく影響されるように，界面の局所的 な電子移動による界面 dipole が異種物質界面のバンドの接 続性に大きな影響を与えると言える(33).

$\mathrm{SBH}$ の定説(金属の仕事関数と半導体の電子親和力の差で 決まるとする説など)は，一般に今回のような界面構造への 依存性を否定する。しかし，最近の実験や第一原理計算は， 界面の原子配列や原子種の重要性を示唆している(34). 今回 の SBH の計算は, 初めて界面の原子配列まで最適化して行 ったものである(もちろん, 数\%のミスフィットの問題が残 っているが). 今後, こうした計算を各種界面に適用するこ とにより SBHのメカニズムの解明が進展する可能性があ る.

\section{5. おわりに}

第一原理擬ポテンシャル法による大規模構造計算の概要と セラミックス界面への適用例を紹介した。安定構造の決定ま で含めた第一原理計算が粒界や異種物質界面に適用できるよ らになったのは，つい最近のことである。最新の電子顕微鏡 技術等と連携することにより, 粒界や界面の研究の大きな進 展が期待できる．最後に，日頃議論いただいているJohn Hoekstra 博士 (大工研 STA フェロー, 現 Oxford 大), 沢村
明賢博士(住友電工)，尾方成信博士(阪大工)に感謝します，

\section{文献}

(1) R. Car and M. Parrinello: Phys. Rev. Lett., 55(1985), 2471.

(2) Quantum Theory of Real Materials, Ed. by J. R. Chelikowsky and S. G. Louie, Kluwer, (1996).

( 3 ) M. Kohyama: Mater. Chem. Phys., 50(1997), 159; submitted to Phys. Rev. B; M. Kohyama and J. Hoekstra: Computer-Aided Design of High-Temperature Materials, Ed. by A. Pechenik et al., Oxford, (1998), in press.

(4) J. Hoekstra and M. Kohyama: Phys. Rev., B 57(1998), 2334 ; 香山正憲 : 高温学会誌, 24(1998), 12.

( 5 ) D. R. Hamann, M. Schlüter and C. Chiang: Phys. Rev. Lett., 43(1979), 1494; G. B. Bachelet, D. R. Hamann and M. Schlüter: Phys. Rev., B 26(1982), 4199.

(6) W. E. Pickett: Comp. Phys. Rep., 9(1989), 115.

( 7 ) J. R. Chelikowsky and M. L. Cohen: Handbook on Semicondutors, vol. 1, Ed. by P. T. Landsberg, Elsevier, (1992), p. 59.

（8）金森順次郎, 米沢富美子, 川村 清, 寺倉清之: 固体-構造之 物性，岩波，(1994）, p. 60.

( 9 ) M. J. Gillan: J. Phys. Condens. Matter, 1(1989), 689.

(10) L. Kleinman and D. M. Bylander: Phys. Rev. Lett., 48(1982), 1425.

(11) T. Oguchi and T. Sasaki: Prog. Theor. Phys. Suppl., 103(1991), 93.

(12) M. C. Payne, M. P. Teter, D. C. Allan, T. A. Arias and J. D. Joannopoulos: Rev. Mod. Phys., 64(1992), 1045.

（13）森川良忠, 寺倉清之: 日本物理学会誌, 48(1993), 428.

(14) K. Terakura: Computational Physics as a New Frontier in Condensed Matter Research, Ed. by H. Takayama et al., The Physical Society of Japan, (1995), p. 1.

(15) R. D. King-Smith and D. Vanderbilt: Phys. Rev., B 49(1994), 5828.

(16) D. M. Bylander, L. Kleinman and S. Lee: Phys. Rev., B 42(1990), 1394.

(17) M. Kohyama: Modelling Simul. Mater. Sci. Eng., 4(1996), 397.

(18) D. Singh: Phys. Rev., B 40(1989), 5428.

(19) G. Kresse and J. Furthmüller: Phys. Rev., B 54(1996), 11169.

(20) G. Galli and M. Parrinello: Computer Simulation in Materials Science, Ed. by M. Mayer and V. Pontikis, Kluwer, (1991), p. 283.

(21) A. M. Rappe, K. M. Rabe, E. Kaxiras and J. D. Joannopoulos: Phys. Rev., B 41(1990), 1227.

(22) N. Troullier and J. L. Martins: Phys. Rev., B 43(1991), 1993.

(23) D. Vanderbilt: Phys. Rev., B 41(1990), 7892.

(24) K. Laasonen, A. Pasquarello, R. Car, C. Lee and D. Vanderbilt: Phys. Rev., B 47(1993), 10142.

(25) P. E. Blöchl: Phys. Rev., B 50(1994), 17953.

(26) K. Hiraga: Sci. Rep. Res. Inst. Tohoku Univ. A, 32 (1984), 1.

（27）田中孝治, 香山正憲, 岩佐美喜男：日本金属学会春期大会講 演概要, (1998), p. 107.

（28）伊藤 彰, 香山正憲, 山本良一：日本金属学会春期大会講演 概要, (1998), p. 166.

(29) J. R. Smith, T. Hong and D. J. Srolovitz: Phys. Rev. Lett., 72(1994), 4021.

（30）尾方成信, 北川 浩 : 日本金属学会誌, 60(1996), 1079.

(31) 須賀唯知 : 私信.

(32) V. M. Bermudez: J. Appl. Phys., 63(1987), 4951.

(33) W. R. L. Lambrecht and B. Segall: Phys. Rev., B 41(1990), 2832.

(34) SBH の解説として, A. P. Sutton and R. W. Balluffi: Interfaces in Crystalline Materials, Oxford, (1995), Sec. 11.2. 